\title{
Evaluation of the Effect of Transobturator Tape Operation Used in Urinary Incontinence Therapy on Sexual Function
}

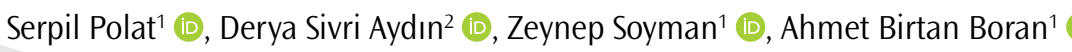

Introduction: To investigate the effect of surgery on sexual function in the preoperative and postoperative period in patients with stress urinary incontinence, who are planned for the transobturator tape (TOT) operation alone.

Methods: The study was prospectively planned. Overall, 33 patients with urinary incontinence, who were diagnosed with stress/mixt urinary incontinence and planned to undergo TOT operation at the Istanbul Education Research Hospital Obstetrics and Gynecology Department and Urology Clinic between January 1, 2010 and January 1, 2015, were enrolled in the study. FSFI scoring was performed before the operation and at least 1 month after the first sexual activity following the operation.

Results: The mean age of the patients was $48.9 \pm 6$ years. The incidence of sexual dysfunction before and after the operation was $42.4 \%(n=14)$. There was no statistically significant difference in the total FSFI score, desire, arousal, orgasm, sexual success, and pain scores between the preoperative and postoperative periods in patients. A statistically significant decrease was found only in the lubrication subscale.

Conclusion: No statistically significant sexual dysfunction was found in women after the TOT operation except for decreased lubrication.

Keywords: Sexual function, transobturator tape, incontinence

ORCID IDs of all authors: S.P. 0000-0002-75012466, D.S.A. 0000-0002-7283-0930; Z.S. 00000002-2678-8989; A.B.B. 0000-0002-4307-7767.

${ }^{1}$ Deparment of Obstetrics and Gynecology, İstanbul Training and Research Hospital, İstanbul, Turkey

${ }^{2}$ Deparment of Obstetrics and Gynecology, İstanbul Haseki Training and Research Hospital, İstanbul, Turkey

Address for Correspondence:

Derya Sivri Aydın

E-mail: deryasivri@hotmail.com

Received: 15.11.2016

Accepted: 20.11.2017

C Copyright 2018 by Available online at istanbulmedicaljournal.org

\section{Introduction}

Urinary incontinence is an involuntary situation that has become a social or hygienic problem (1). The frequency of the problem increases with age, and it can be considered as a condition that is insignificant and whose treatment is unnecessary or impossible. However, urinary incontinence is a health problem known to cause serious social, hygienic, emotional, and sexual issues $(2,3)$.

Stress urinary incontinence (SUI) is defined as involuntary leakage of urine while coughing or sneezing or during physical exercise. Its prevalence has been reported to be $25 \%$ among women worldwide and 35\% in European countries $(1,4)$. In SUI treatment, in addition to pelvic floor exercises, behavior therapy, biofeedback, and electrical stimulation, surgical treatment is applied in patients who do not respond to other treatment. Many surgical procedures have been defined for SUI therapy. The transobturator tape (TOT) technique is a suburethral sling operation developed by Delorme (5) and is currently used as the standard surgical treatment for SUI.

Sexual dysfunction is seen in up to $50 \%$ of women with SUI or urinary system dysfunction (6). Although sexual function recovers with the correction of pelvic floor deficiency, surgical and operative materials may cause sexual dysfunction in some patients. Sexual function should be assessed before treatment (7). The Female Sexual Function Index (FSFI) is a form that is used for this purpose and comprises 19 questions about arousal, sexual desire, orgasm, lubrication, sexual satisfaction, and pain in the last 4 weeks (8). In the present study, in patients who had SUI and in whom TOT operation alone was planned, we aimed to investigate the effect of operation on sexual function in the preoperative and postoperative periods using FSFI.

\section{Methods}

The study was planned as a prospective study, and 151 sexually active patients consulted to the Obstetrics and Gynecology Clinic and the Urology Clinic of İstanbul Training and Research Hospital between January 1, 2010, and January 1, 2015. They had complaints of urinary incontinence or consulted due to other reasons, and they were found to have stress/mixed incontinence after questioning and examination; however, 118 patients in whom prolapse operation was performed in addition to the TOT operation and in whom preoperative and postoperative complications developed were excluded from the study. 
Thirty-three patients in whom urinary incontinence was found while standing or in a gynecological position with coughing or straining, or those who had stress/mixed urinary incontinence and for whom TOT operation was scheduled, were included in the study. Informed consent was received from all the patients included in the study. In the preoperative and postoperative periods, FSFI scoring was performed in the patients at least 1 month after being sexually active.

The patients were questioned about age, height, weight, smoking, menopausal status, menopause duration, number of births, delivery type (vaginal delivery or cesarean section), large fetus history, monthly average income, education level, and whether or not they had urinary incontinence during sexual intercourse. Patients were categorized as 500-1,000 TL, 100-1,500 TL, and 1,500 TL in terms of the average monthly income and as no education, primary school, secondary school, high school, and university in terms of education level.

The patients filled out the FSFI forms, comprising 19 items with questions about sexual function, before and after the operation (at least 1 month after being sexually active). In the content of the scale, there were six sub-sections: arousal, desire, lubrication, satisfaction, orgasm, and pain. Each section was scored from 0 to 5. Sexual desire or frequency and level of interest was evaluated in the $1^{\text {st }}$ and $2^{\text {nd }}$ questions (Score: $1-5$ ); frequency and level of arousal, certainty, and satisfaction in the $3^{\text {rd }}$ and $6^{\text {th }}$ questions (Score: 0-5); frequency and difficulty of lubrication and the ability to maintain it during sexual intercourse in the $7^{\text {th }}$ and $10^{\text {th }}$ questions (Score: 0-5); frequency, difficulty, and satisfaction of orgasm in the $11^{\text {th }}$ and $13^{\text {th }}$ questions (Score: $0-5$ ); satisfaction, sympathy to the partner, and level of satisfaction in sexual relations and in all sexual life in the $14^{\text {th }}$ and $16^{\text {th }}$ questions (Score: $0-1-5$ ); and pain or discomfort, pain during entry into the vagina, and level of pain felt after entry in the $17^{\text {th }}$ and $19^{\text {th }}$ questions (Score: $0-5$ ).

The highest score in the scale was 95, and the lowest score was 4. The calculation was designed to determine the scoring of the subdivisions and the whole scale, and the coefficient was determined as 0.6 for desire, 0.3 for arousal and lubrication, and 0.4 for orgasm, satisfaction, and pain. When the averages of subdivisions were multiplied by the coefficients, the highest score that could be obtained was calculated as 36 and the lowest score as 2 (9). The size of the sample to be included in the study was calculated according to the study of El-Enen et al. (10) Based on the total FSFI difference, the minimum sample size was determined to be six with $80 \%$ power and 0.05 a error.

Ethics committee approval was received before the study.

\section{Statistical Analysis}

Descriptive statistics using SPSS 15.0 for Windows (SPSS Inc.; Chicago, IL, USA) are presented as number and percentage for categorical variables and as mean \pm standard deviation and minimum-maximum for numerical variables. Independent two-group comparisons were performed using Student's t-test when the normal distribution condition was achieved; multiple group comparisons were performed with one-way ANOVA test. Independent two-group comparisons were performed using Mann-Whitney U-test when the normal distribution condition was not achieved, and multiple group comparisons were performed with the Kruskal-Wallis test. Subgroup analyses were performed with the Tukey test because parametric performed with paired t-tests when the differences of variables had a normal distribution condition and with Wilcoxon test when it was not normal. Relationships among numerical variables were analyzed with Pearson correlation analysis when a parametric test condition was provided and with Spearman correlation analysis when it was not provided. $p<0.05$ was accepted as the level of statistical alpha significance.

\section{Results}

Of the 33 patients included in the present study, 20 were operated on by surgeons in the Department of Obstetrics and Gynecology and 13 by surgeons in the Department of Urology.

The mean age of the patients was $48.9 \pm 6$ years (35-63 years), mean gravida was 4.1 \pm 1.8 (2-10), mean parity was $2.3 \pm 0.8$ (1-4), and mean BMI was $29.1 \pm 4.3(23-40)$. Of the patients, $39.4 \%(n=13)$ were in the menopausal period, and the mean menopause duration was 6 years; $75.8 \%(n=25)$ of the patients had a natural birth, and birth weights ranged from 4800 to $1750 \mathrm{~g}$. Of the patients, $27.3 \%(n=9)$ smoked, $3 \%$ of them had no education, $75.8 \%$ were primary school graduates, $3 \%$ were secondary school graduates, $15.2 \%$ were high school graduates, and $3 \%$ were university graduates. Monthly income was $500-1,000 \mathrm{TL}$ in $27.3 \%$ of the patients, $1,000-1,500$ TL in $36.4 \%$, and $>1,500$ TL in $36.4 \%$.

While $54.5 \%(n=18)$ of the patients had incontinence during sexual intercourse before the operation, only $6.1 \%(n=2)$ had incontinence after the operation.

The results of the FSFI scale before and after the operation are summarized in the Table. Postoperatively, the decrease in the mean FSFI subscale scores of desire, arousal, orgasm, sexual success, and pain was not statistically significant $(p>0.05)$. While the mean FSFI score was $4.8 \pm 1.2$ for the lubrication subscale, it was $4.4 \pm 1.4$ after the operation. This decrease in lubrication was statistically significant $(p=0.037)$. While the mean total FSFI score was $25.9 \pm 5.3$ preoperatively, it was $24.5 \pm 5.9$ after the operation; however, the decrease was not statistically significant $(p=0.277)$.

The rate of sexual dysfunction before and after the operation was found to be $42.4 \%$ ( $n=14)$. Two patients who had sexual dysfunction preoperatively recovered after the operation; nevertheless, the total score did not change because sexual dysfunction occurred in two patients who did not have sexual dysfunction preoperatively.

There was a statistically significant negative correlation between the preoperative total FSFI score and parity $(p=0.019)$. Among the subscales, the arousal score showed a positive correlation with high birth weight, the sexual success score showed a negative correlation with parity, and the pain score showed a positive correlation with the excessive value of the highest birth weight ( $p=0.043$, $p=0.016, p=0.017$, respectively). The relationship between FSFI subgroups and age, BMI, gravida, and menopause duration was not statistically significant before the operation $(p>0.05)$.

The preoperative total FSFI scores and the scores of desire and orgasm subscales were statistically significantly lower in uneducated patients and primary-secondary school graduates than in high school and university graduates $(p=0.023, p=0.028, p=0.026$, respectively). There was a statistically significant difference in the 
Table 1. Evaluation of FSFI scores before and after the TOT operation

\begin{tabular}{lccccc} 
& \multicolumn{2}{c}{ Before Treatment } & \multicolumn{2}{c}{ After Treatment } \\
\cline { 2 - 5 } & Mean \pm SD & Min-Max & Mean \pm SD & Min-Max & p \\
\hline Desire & $3.4 \pm 1.1$ & $1.2-6$ & $3.2 \pm 1.2$ & $1.2-6$ & 0.14 \\
\hline Arousal & $3.6 \pm 1.1$ & $1.5-6$ & $3.4 \pm 1.1$ & $1.2-6$ & 0.479 \\
\hline Lubrication & $4.8 \pm 1.2$ & $1.5-6$ & $4.4 \pm 1.4$ & $1.8-6$ & 0.037 \\
\hline Orgasm & $4.6 \pm 1.1$ & $1.2-6$ & $4.3 \pm 1.3$ & $1.2-6$ & 0.09 \\
\hline Sexual success & $4.7 \pm 1.2$ & $1.2-6$ & $4.5 \pm 1.3$ & $1.2-6$ & 0.188 \\
\hline Pain & $4.8 \pm 1.3$ & $2.0-6$ & $4.6 \pm 1.2$ & $2.0-6$ & 0.589 \\
\hline Total score & $25.9 \pm 5.3$ & $11.7-35$ & $24.5 \pm 5.9$ & $8.6-34.2$ & 0.277 \\
\hline SD: standart deviation; Min: minimum; Max: maximum & & & & &
\end{tabular}

groups of monthly income level in terms of the pretreatment total FSFI scores and the arousal subscale scores. The total score of the group with a monthly income level $>1,500$ TL was statistically significant in comparison with the group with a monthly income of 1,000-1,500 TL and with the group with a monthly income of 500-1.000 TL ( $p=0.027, p=0.002, p=0.039$, respectively).

No association was found between the preoperative FSFI subgroups and delivery type, menopausal status, and incontinence status during sexual intercourse $(p>0.05)$.

The postoperative total FSFI scores and the scores of desire, arousal, orgasm, and sexual success subscales were found to be statistically significantly correlated with age and parity in a negative manner $(p<0.05)$. There was no statistically significant relationship between lubrication and pain subscales in terms of age and parity after treatment $(p>0.05)$.

The postoperative total FSFI scores and the scores of desire, arousal, orgasm, sexual success, and pain subscales showed no statistically significant relationship with age, BMI, gravida, and menopause duration $(p>0.05)$.

The postoperative total FSFI scores and the scores of desire and orgasm subscales were found to be statistically significantly lower in uneducated people and in primary-secondary school graduates than in high school and university graduates $(p=0.032, p=0.015$, $p=0.022$, respectively), but no relationship was observed in arousal, lubrication, sexual success, and pain scores $(p=0.05)$.

The total FSFI score and the scores of desire, arousal, and sexual success subscales were statistically significantly lower in menopausal women than in non-menopausal women $(p=0.006$, $p=0.046, p=0.001, p=0.008$, respectively), but no correlation was observed in the lubrication, orgasm, and pain subscales $(\mathrm{p}>0.05)$.

The score of sexual success subscale of those who did not experience urinary incontinence during sexual intercourse after the operation was statistically significantly lower than those who had urinary incontinence $(p=0.017)$.

There was no statistically significant relationship in total FSFI scores and subscales in terms of monthly income, type of delivery, and cigarette use $(p>0.05)$.

\section{Discussion}

Sexual dysfunction in women is a common condition that is frequently encountered in pelvic floor insufficiency, and existing studies have suggested that sexual function also improves after pelvic floor disorders have been corrected; however, it is thought that the operation and materials used may cause sexual dysfunction in some patients. In these patients, sexual function needs to be assessed before treatment, and this assessment can be done effectively with a questionnaire and by scoring the symptoms (9).

Although the relationship between urinary incontinence and female sexual dysfunction has been studied for a long time, some points in this subject are still unclear, and the results obtained are contradictory. The number of researches conducted in this regard is high, but the number of studies that are academically sound, evidence-based, and valuable in terms of medicine is limited. The most important reason for this is that both pathologies have physiological, psychological, and social dimensions and that it is difficult for the research to reflect all dimensions. In contrast, the difficulty in establishing tests used to evaluate these difficult-to-measure concepts cannot be denied. Because most women avoid talking about incontinence and sexual dysfunction, the frequency remains below normal. Due to urinary incontinence, there may be anxiety, loss of self-esteem, and decreased sexual desire (7).

Although urinary incontinence and sexual dysfunction are related to each other, there are few studies indicating that incontinence surgeries have an effect on sexual function (10-12).

It has been reported that sexual function may improve after incontinence operation, but the operation may also have adverse effects on sexual function due to impaired vaginal innervation $(13,14)$.

It has been reported that urinary incontinence causes female sexual dysfunction and that the incidence of sexual dysfunction in women with urinary incontinence is between $26 \%$ and $43 \%$ (15). Sexual dysfunction has been detected in $48.3 \%$ of the women in our country. In our study, the incidence of sexual dysfunction was found to be $42.4 \%$ in patients with SUI, which did not change after the operation. This result suggests that the TOT operation does not affect sexual function negatively. 
In a study conducted by Shaw (16), sexual dysfunction was observed in $46 \%$ of patients with urinary incontinence and lower urinary tract complaints. It has been reported by Barber et al. (17) that $11 \%-77 \%$ of women have urinary incontinence during sexual intercourse. It has also been reported by Barber that the most frequent urinary incontinence is SUI (18). In a study conducted by Clark and Romm (19), 56\% of the cases were reported to have urinary incontinence during sexual intercourse, and this affected their sexual life negatively. In our study, incontinence was observed in $54.5 \%$ $(n=18)$ of the patients during sexual intercourse before the operation, which was consistent with the literature, and only $6.1 \%(n=2)$ of the patients had incontinence after the operation.

Midurethral sling operations are the most frequently used in the treatment of SUI. These operations have been shown to have a positive effect on sexual function after the operation, but there are also studies arguing against it. Erosion resulting from the complication of sling operations is important in this negative effect. There are also studies that show that hemorrhage in the vaginal anterior wall and impaired innervation can lead to orgasm impairment. It has been demonstrated in some studies that vaginal stenosis or laxity may also cause sexual dysfunction. Dursun et al. (20) evaluated 96 women who underwent TOT. In that study, the total FSFI score was found to be statistically insignificant in the increase in the scores of arousal, desire, orgasm, and lubrication, but a statistically significant improvement was observed in pain and satisfaction scores. In our study, a decrease in the mean FSFI scores of desire, arousal, orgasm, sexual success, and pain subscales was observed after the operation compared with before; however, this decrease was not statistically significant. The decrease detected in the lubrication subscale was statistically significant. This can be attributed to the high average age of the population of the study.

As the age of women increases, sexual desire, orgasm, arousal, lubrication, and satisfaction decrease; in contrast, there is an increase in pain during sexual intercourse. Estrogen decrease has been shown to cause dyspareunia, loss of desire, decrease in the number of sexual activities, decrease in genital sensitivity, and difficulty in reaching orgasm; testosterone decrease has been shown to cause a decrease in sexual genital sensitivity, arousal, and libido as well as difficulty in reaching orgasm (21). In our study, the total FSFI score and the scores of desire, arousal, orgasm, and sexual success subscales of the patients after the operation were statistically significantly correlated with age in a negative way, and the total FSFI score and the scores of desire, arousal, and sexual success subscales were statistically significantly lower in menopausal patients than in non-menopausal patients. Lubrication, orgasm, and pain, which are FSFI scale subgroups, were not statistically significantly related to menopausal status after the operation.

Although the adverse effects of multiparity on sexual function have been reported, it has also been reported that there is no significant relationship between parity and female sexual function $(22,23)$. In our study, the pretreatment total FSFI score and sexual success score were statistically significantly correlated with parity in a negative manner. After the operation, the total FSFI score and the scores of desire, arousal, orgasm, and sexual success subscales were statistically significantly correlated with parity in a negative manner.

The effect of the education level of women on sexual function is

known. Çayan et al. (24) observed a positive relationship between the education level of women and the FSFI subscales. It has been found that the presence of sexual problems increases with low education levels (25). In accordance with the literature, in our study, the pretreatment total FSFI score and the scores of desire and orgasm subscales were statistically significantly lower in noneducated patients and primary-secondary school graduates than in high school and university graduates. The post-treatment total FSFI score and the scores of desire and orgasm subscales were statistically significantly lower in non-educated patients and primarysecondary school graduates than in high school and university graduates.

\section{Conclusion}

We found no statistically significant difference in the total FSFI scores and the scores of desire, arousal, orgasm, sexual success, and pain of the patients who had SUI and underwent TOT operation. We found a statistically significant decrease only in the lubrication subscale. Menopausal status and parity at advanced ages are also risk factors for female sexual dysfunction. The education levels of women are an important factor affecting their sexual function. In this study, except for lubrication decrease, no statistically significant sexual dysfunction was detected in women after the TOT operation. However, in this respect, there is still a gap in studies that are academically sound, evidence-based, and valuable in terms of medicine, and there is a need for more comprehensive studies.

Ethics Committee Approval: Ethics committee approval was received for this study from the ethics committee of istanbul Training and Research Hospital (Approval Date: 29.05.2015; Approval No: 661).

Informed Consent: Informed consent was obtained from the patients who participated in this study.

Peer-review: Externally peer-reviewed.

Author Contributions: Concept - D.S.A.; Design - D.S.A., S.P.; Supervision S.P., D.S.A., Z.S., A.B.B.; Resource - S.P.; Materials - S.P.; Data Collection and/or Processing - S.P.; Analysis and/or Interpretation - D.S.A., S.P.; Literature Search - D.S.A., S.P.; Writing - D.S.A., S.P., Z.S., A.B.B.; Critical Reviews - D.S.A., A.B.B.

Conflict of Interest: The authors have no conflict of interest to declare.

Financial Disclosure: The authors declared that this study has received no financial support.

\section{References}

1. Abrams P, Blaivas JG, Stanton SL, Andersen JT. The standardisation of terminology of lower urinary tract function. Int Urogynecol J 1990; 1: 45-58. [CrossRef]

2. Kişnișçi HA, Gökşin E, Durukan T, Üstay K, Ayhan A, Gürgan T, et al. Temel Kadın Hastalıkları ve Doğum Bilgisi. Güneş Kitabevi, Ankara, 1996; 730-47.

3. Berek JS. Novak's Gynecology. 14th Edition. Lippincott Williams\&Wilkins. 2006.

4. Hunskaar S, Lose G, Sykes D, Voss S. The prevalence of urinary incontinence in women in four European countries. BJU Int 2004; 93: 324-30. [CrossRef]

5. Delorme E. [Transobturator urethral suspension: Mini-invasive procedure in the treatment of stress urinary incontinence in women]. Prog Urol 2001; 11: 1306-13. [Article in French]

6. Dalpiaz O, Kerschbaumer A, Mitterberger M, Pinggera GM, Colleselli D, Bartsch G, et al. Female sexual dysfunction: A new urogynaecological research field. BJU Int 2008; 101: 717-21. [CrossRef] 
7. Özdedeli K, Yüksel İ. Pelvik Taban Bozuklukları ve Kadın Cinsel Fonksiyon Bozukluğu. Kadın ve İşlevsel Üroloji Dergisi 2014; 3: 73-7. [CrossRef]

8. Rosen R, Brown C, Heiman J, Leiblum S, Meston C, Shabsigh R, et al. The Female Sexual Function Index (FSFI): a multidimensional selfreport instrument for the assessment of female sexual function. J Sex Marital Ther 2000; 26: 191-208. [CrossRef]

9. Leppert PC, Howard FM. Primary Care for Women, Quebecor/Kingsport, Philadelphia, 1997.

10. El-Enen MA, Ragb M, El Gamasy Ael-N, El-Ashry O, El-Sharaby M, Elbadawy A, et al. Sexual function among women with stress incontinence after using transobturator vaginal tape, and its correlation with patient's expectations. BJU Int 2009; 104: 1118-23. [CrossRef]

11. Koçak I, Okyay P, Dundar M, Erol H, Beser E. Female urinary incontinence in the West of Turkey: Prevalence, risk factors and impact on quality of life. Eur Urol 2005; 48: 634-41. [CrossRef]

12. Zippe CD, Raina R, Shah AD, Massanyi EZ, Agarwal A, Ulchaker J, et al. Sexual dysfuntion after radical cystectomy: a new outcome measure. Urology 2004; 63: 1153-7. [CrossRef]

13. Elzevier HW, Venema PL, Lycklama á Nijeholt AA. Sexual function after tension-free vaginal tape (TVT) for stress incontinence: results of a mailed questionnaire. Int Urogynecol J Pelvic Dysfunct 2004; 15: 3138. [CrossRef]

14. Glavind K, Tetsche MS. Sexual function in women before and after suburetral sling operation for stres urinary incontinence: a retrospective questionnaire study. Acta Obstet Gynecol Scand 2004; 83: 965-8. [CrossRef]

15. Oksuz E, Malhan S. Prevalence and risk factors for female sexual dysfunction in Turkish women. J Urol 2006; 175: 654-8. [CrossRef]

16. Shaw C. A systematic review of the literature on the prevelance of the sexual impairment in women with urinary incontinence and the prevelance of urinary leakage during sexual activity. Eur Urol 2002; 42: 432-40. [CrossRef]
17. Barber MD, Dowsett SA, Mullen KJ, Viktrup L. The impact of stress urinary incontinence on sexual activity in women. Cleve Clin J Med. 2005; 72: 225-32. [CrossRef]

18. Barber MD, Visco AG, Wyman JF, Fantl JA, Bump RC, Continence Program for Women Research Group. Sexual function in women with urinary incontinence and pelvic organ prolapse. Obstet Gynecol 2002; 99: 281-9. [CrossRef]

19. Clark A, Romm J. Effect of urinary incontinence on sexual activitiy in women. J Reprod Med 1993; 38: 679-83.

20. Dursun M, Otunctemur A, Ozbek E, Cakir SS, Polat EC. Impact of the transobturator tape procedure on sexual function in women with stress urinary incontinence. J Obstet Gynaecol Res 2013; 39: 831-5. [CrossRef]

21. Jennifer R, Berman MD, Irwin Goldstein MD. Female sexual dysfunction. Urol Clin North Am 2001; 28: 405-16. [CrossRef]

22. Lukacz ES, Whitcomb EL, Lawrence JM, Nager CW, Contreras R, Luber KM. Are sexual activity and satisfaction affected by pelvic floor disorders? Analaysis of a community-based survey. Am J Obstet Gynecol 2007; 197: 1-6. [CrossRef]

23. Handa VL, Harvey L, Cundiff GW, Siddique SA, Kjerulff KH. Sexual function among women with urinary incontinence and pelvic organ prolapse. Am J Obstet Gynecol 2004; 191: 751-6. [CrossRef]

24. Çayan S, Akay E, Bozlu M, Canpolat B, Acar D, Ulusoy E. The prevelance of female sexual dysfunction and potential risk factors that may impair sexual function in Turkish women. Urol Int 2004; 72: 52-7. [CrossRef]

25. Laumann EO, Paik A, Rosen RC. Sexual dysfunction in the United States: prevalence and predictors. JAMA 1999; 281: 537-44. [CrossRef]

Cite this article as: Polat S, Aydın DS, Soyman Z, Boran AB. Evaluation of the Effect of Transobturator Tape Operation Used in Urinary Incontinence Therapy on Sexual Function. İstanbul Med J 2018; 19: 129-33. 